\title{
PENGARUH JARAK ANTAR FIN PADA SILINDER BERSIRIP TERHADAP SEPARASI ALIRAN DI PERMUKAAN SILINDER DAN FIN
}

\author{
Sudirman \\ Jurusan Teknik Mesin, Fakultas Teknik, Universitas Borneo Tarakan \\ E-mail: sudirman_dhuha@yahoo.co.id

\section{Ruslim} \\ Jurusan Teknik Mesin, Fakultas Teknik, Universitas Borneo Tarakan \\ E-mail: ruslim1974@gmail.com

\section{Abstrak}

Fluida yang mengalir melewati objek akan memberikan pengaruh yang cukup signifikan berupa gaya angkat dan gaya drag pada permukaannya. Besar gaya-gaya ini tergantung pada kecepatan aliran freestream, profil aliran, kondisi permukaan benda, bentuk maupun orientasi benda yang dilintasi. Pada bluff body, gaya drag didominasi oleh pressure drag sedangkan pada streamlined body, didominasi oleh skin friction drag. Efek viskositas memberikan kontribusi terhadap gesekan sehingga fluida pada boundary layer kehilangan energi selama mengalir. Hal ini dapat menimbulkan separasi aliran di permukaan benda jika dikombinasikan dengan kenaikan tekanan. Semakin cepat separasi aliran terbentuk, maka luas daerah wake semakin besar. Pada penelitian ini, diamati silinder bersirip dengan variasi jarak antar fin untuk mengetahui pengaruh fin pitch tersebut terhadap separasi aliran di permukaan fin.

Benda uji berupa silinder sirkular diameter $25 \mathrm{~mm}$ ditambahkan annular fin pada permukaannya dengan tebal fin $2 \mathrm{~mm}$. Pengaruh jarak antar fin dengan variasi $10 \mathrm{~mm}, 14 \mathrm{~mm}$, dan $18 \mathrm{~mm}$ terhadap separasi aliran di permukaan fin diamati dengan metode simulasi numerik menggunakan software Fluent 6.3 dengan bilangan Reynolds 2,5 x $10^{4}$ berdasarkan diameter silinder dan kecepatan rata-rata inlet.

Hasil pengamatan menunjukkan semakin rapat jarak antar fin, separasi aliran yang terjadi pada ruang antar fin terjadi lebih awal. Ketika jarak antar fin meningkat, posisi separasi aliran dan vorteks di permukaan fin bergerak mendekat ke daerah di belakang silinder. Hal ini menunjukkan bahwa udara tidak mengalir dengan baik pada daerah tersebut untuk fin pitch yang sempit.

Kata Kunci: Silinder bersirip, separasi aliran, jarak antar fin.

\begin{abstract}
Fluid flowing through the object will give a significant influence in the form of lift and drag force on the surface. The magnitude of these forces depends on the speed of the free-stream flow, flow profile, surface condition of the object, the shape or orientation of the object being traversed. In bluff body, drag force is dominated by pressure drag while in streamlined body, dominated by skin friction drag. The viscosity effect contributes to friction so that the fluid on the boundary layer loses energy during flow. This can cause flow separation on the surface of the object when combined with the increase in pressure. The faster the flow separation is formed, the larger the wake area. In this study, we observed finned cylinders with variations of the fin distance to determine the effect of the fin pitch on the flow separation at the fin surface.

Test specimens of circular cylinder diameter $25 \mathrm{~mm}$ added annular fin on the surface with fin thickness 2 $\mathrm{mm}$. The effect of fin distance between the variations of $10 \mathrm{~mm}, 14 \mathrm{~mm}$, and $18 \mathrm{~mm}$ on the flow separation at the fin surface was observed by numerical simulation method using Fluent 6.3 software with Reynolds number $2.5 \times 10^{4}$ based on cylinder diameter and average speed of inlet. The observations show the closer the distance between fin, the separation of flow that occurs in the space between the fin occurs earlier. As the fin distance increases, the position of the flow separation and the vortex on the fin surface moves closer to the area behind the cylinder. This shows that air does not flow well in the area for a narrow fin pitch.
\end{abstract}

Keywords: Finned cylinder, flow separation, spacing between fin. 


\section{PENDAHULUAN}

Interaksi antara aliran fluida dan benda berbentuk bluff body (benda tumpul) maupun streamlined body (benda berbentuk ramping) yang diam maupun bergerak banyak ditemui dalam aplikasi teknik. Alat penukar kalor, kontruksi bangunan lepas pantai, jembatan, dan alat-alat transportasi adalah diantara dari sekian banyak bidang yang perancangannya dipengaruhi oleh sifat aliran fluida. Fluida yang mengalir melewati objek akan memberikan pengaruh yang cukup signifikan berupa gaya angkat dan gaya drag pada permukaannya. Besar gaya-gaya ini tergantung pada kecepatan aliran free-stream, profil aliran, kondisi permukaan benda, bentuk maupun orientasi benda yang dilintasi. Pada bluff body, gaya drag didominasi oleh pressure drag sedangkan pada streamlined body, umumnya didominasi oleh skin friction drag (Widodo dkk, 2009). Efek viskositas memberikan kontribusi terhadap gesekan sehingga fluida pada boundary layer kehilangan energi selama mengalir. Hal ini dapat menimbulkan separasi aliran di permukaan benda jika dikombinasikan dengan kenaikan tekanan. Semakin cepat separasi aliran terbentuk, maka luas daerah wake semakin besar. Triyogi dkk (2009) telah melakukan pengujian penundaan separasi aliran benda berbentuk silinder sirkular dengan memasang silinder tipe I pada upstream. Khashehchi dkk (2014) membandingkan wake yang terjadi di belakang silinder bersirip dan foamed cylinder.

Beberapa contoh studi di atas menggunakan objek penelitian silinder sirkular dengan fin berbentuk gelang (annular fins) yang penggunaannya banyak ditemui sebagai pendinginan udara internal engine combustion maupun alat penukar kalor. Laju perpindahan panas akan meningkat dengan meningkatnya jumlah fin pada silinder, namun pada aliran udara rendah, pendinginan silinder akan berkurang dengan penyempitan jarak antar fin akibat penambahan jumlah fin. Hal tersebut disebabkan udara tidak mengalir dengan baik pada ruang antar fin (Yoshida dkk, 2006). Penambahan objek pada domain aliran fluida akan memberikan kontribusi terhadap pressure drop aliran (Pis'mennyi dkk, 2014), sehingga hal tersebut menjadi hal yang harus dipertimbangkan dalam perancangan teknik. Berdasarkan hal tersebut, pengetahuan tentang karakeristik aliran fluida melalui silinder bersirip menjadi cukup penting untuk diamati. Pada penelitian ini akan fokus membahas bagaimana pengaruh fin pitch terhadap separasi aliran di permukaan silinder dan permukaan fin.

\section{METODE}

Penelitian ini dilakukan dengan simulasi numerik menggunakan software Gambit 2.4 dan Fluent 6.3. Pada gambar 1 ditampilkan model silinder bersirip dengan variasi jarak antar fin yang digunakan pada penelitian ini. Parameter penelitian yang digunakan secara lengkap ditampilkan pada tabel 1. Diameter silinder, panjang silinder, panjang fin, dan tebal fin adalah variabel yang tetap konstan. Variabel yang diubah adalah jarak antar fin, yaitu $10 \mathrm{~mm}, 14 \mathrm{~mm}$, dan $18 \mathrm{~mm}$. Jarak antar fin dan panjang fin yang dipilih berada pada batas nilai eksperimen yang dilakukan oleh Pis'mennyi (2012), yaitu masing-masing $4 \mathrm{~mm} \mathrm{~s} / \mathrm{d} 20 \mathrm{~mm}$ dan $12.0 \mathrm{~mm} \mathrm{~s} / \mathrm{d} 48.5$ $\mathrm{mm}$. Geometri yang digunakan pada penelitian tersebut telah disesuaikan dengan parameter yang banyak diterapkan di industri. Selain itu penentuan dimensi objek penelitian telah disesuaikan dengan dimensi wind tunnel agar blockage ratio tidak lebih dari $10 \%$.

Tabel 1 Dimensi objek dan variasi penelitian dalam $\mathrm{mm}$

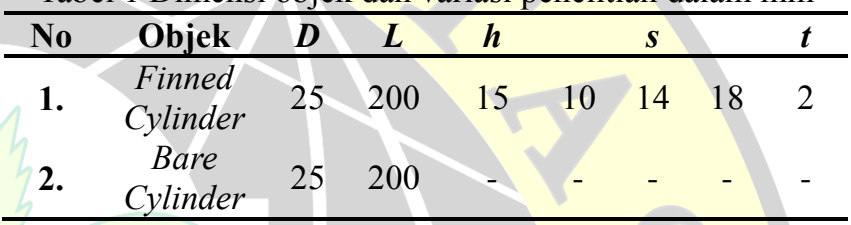

Keterangan:

$d=$ diameter silinder $\quad s=$ jarak antar fin (fin pitch)

$L=$ panjang silinder $\quad t=$ tebal fin

$h=$ panjang fin

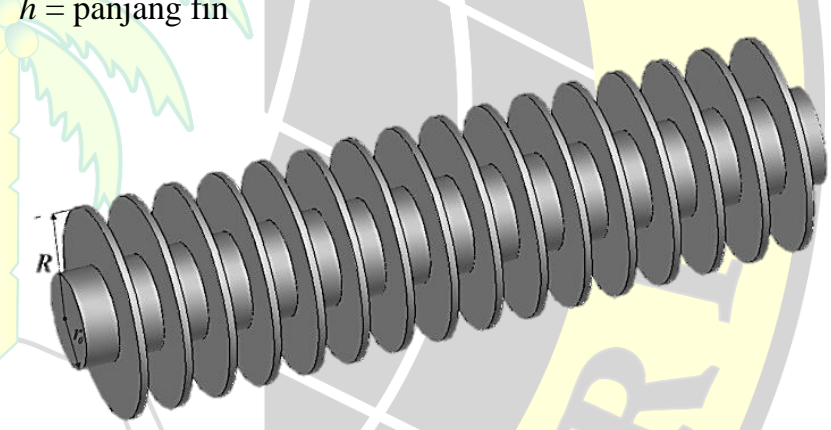

Gambar 1. Model objek penelitian

Simulasi numerik pada penelitian ini dilakukan dengan pendekatan 3D-steady flow Reynolds Averaged-Navier Stokes (RANS) dan RNG k- $\boldsymbol{\varepsilon}$. Properties udara yang digunakan pada kondisi STP dengan temperatur $28{ }^{\circ} \mathrm{C}$ adalah, densitas $(\rho)=1,17 \mathrm{~kg} / \mathrm{m}^{3}$ dan viskositas $(\mu)=$ $1,85 \times 10^{-5} \mathrm{~N} . \mathrm{s} / \mathrm{m}^{2}$. Kondisi inlet aliran udara, velocity inlet $16 \mathrm{~m} / \mathrm{s}$ dan intensitas turbulensi $1,56 \%$ diterapkan pada kondisi batas inlet domain simulasi numerik. 


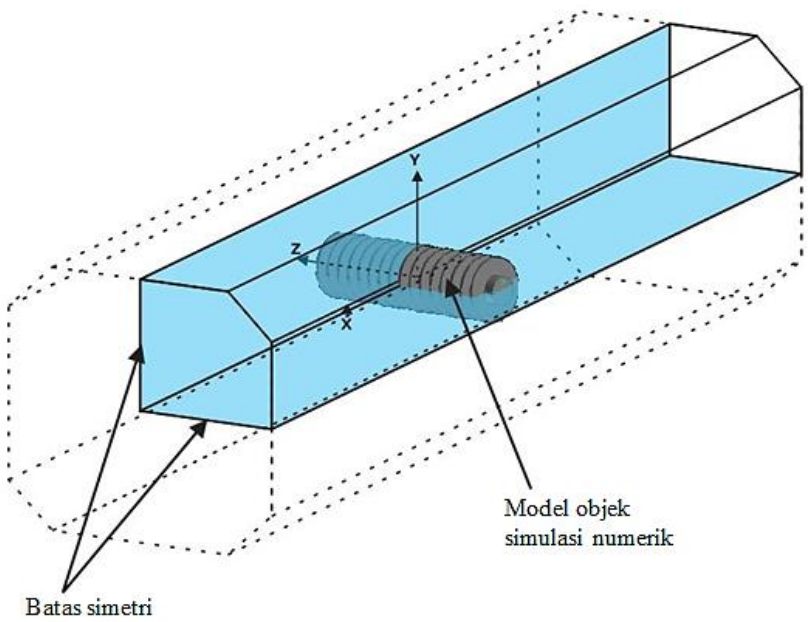

Gambar 2. Model simetris 3D pada simulasi numerik silinder bersirip

Silinder bersirip yang menjadi objek pengamatan pada penelitian ini merupakan bentuk benda yang simetris, demikian pula bentuk saluran yang digunakan. Pada kondisi steady, diperkirakan medan aliran yang terbentuk akan simetris, maka pada penelitian ini digunakan batas simetri (symmetry boundary). Domain simulasi dan kondisi batas ditunjukkan pada gambar 2, domain simulasi numerik ditentukan masing-masing $8 d$ dan $28 d$ dari sisi inlet dan sisi outlet terhadap titik pusat silinder. Jarak terhadap dinding atas sebesar $6 d$ disesuaikan dengan dimensi wind tunnel pengujian eksperimen, dimana $d$ adalah diameter silinder.

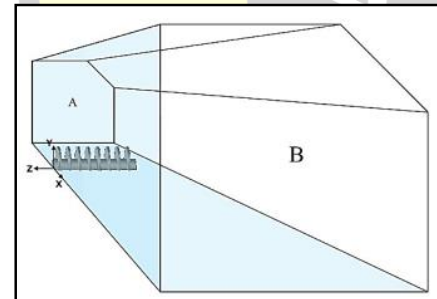

(a)

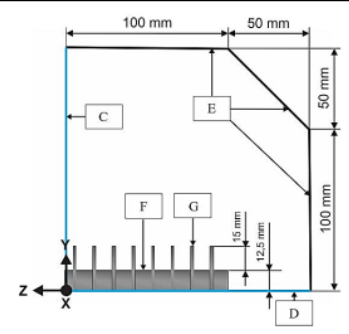

(b) meshing yang digunakan dalam penelitian ini adalah meshing $\mathrm{C}$ dengan error nilai $C_{D}$ yang terkecil $1,59 \%$.

Tabel 2 Grid independensi silinder sirkular tanpa fin.

\begin{tabular}{ccccc}
\hline Meshing & Faces & $\boldsymbol{C}_{\boldsymbol{D}}$ & $\boldsymbol{C}_{\boldsymbol{D}}{ }^{*}$ & Error $\mid$ \\
\hline A & 582.166 & 1,028 & 1,26 & $18,41 \%$ \\
B & 612.066 & 1,064 & 1,26 & $15,56 \%$ \\
C & 671.866 & 1,24 & 1,26 & $1,59 \%$ \\
D & 701.766 & 1,31 & 1,26 & $3,97 \%$ \\
E & 731.666 & 1,326 & 1,26 & $5,24 \%$ \\
\hline
\end{tabular}

*(Ladjedel dkk, 2011)

\section{HASIL DAN PEMBAHASAN}

Distribusi Koefisien Tekanan $\left(C_{P}\right)$ di Permukaan Silinder

Profil kecepatan di belakang silinder sirkular dan silinder bersirip dengan jarak antar fin $10 \mathrm{~mm}, 14 \mathrm{~mm}$, dan 18 $\mathrm{mm}$ hasil simulasi numerik ditampilkan pada gambar 4.3. Trend grafik profil kecepatan di belakang silinder sirkular lebih sempit dibandingkan profil kecepatan di belakang silinder bersirip lainnya. Profil kecepatan semakin besar secara bertingkat dimulai dari profil kecepatan di belakang silinder bersirip dengan $s=18 \mathrm{~mm}, s=14 \mathrm{~mm}$, dan $s=10 \mathrm{~mm}$, hal ini identik dengan hasil eksperimen pengukuran profil kecepatan pada gambar 4.1.

Kecepatan aliran di belakang silinder sirkular pada daerah $x / d=4$ saat $y / d=1.5$, mulai mengalami penurunan dari kecepatan freestream sebagai pengaruh dari separasi aliran yang terbentuk di permukaan silinder. Kecepatan terus berkurang hingga $y / d=0.5$ atau tepat berada di belakang silinder sirkular, dimana pengaruh vorteks aliran semakin besar (sebagaimana akan ditampilkan pada pembahasan contour kecepatan) sehingga keceparan udara turun dengan cukup signifikan hingga bidang simetris.
Keterangan :

$\mathrm{A}=$ Inlet (velocity inlet)

$\mathrm{B}=$ Outlet (out flow)

$\mathrm{C}=$ Potongan simetri 1

(symmetry)

$\mathrm{D}=$ Potongan simetri 2

(symmetry)
$\mathrm{E}=$ Dinding atas dan

samping (wall)

$\mathrm{F}=\operatorname{Silinder}($ wall $)$

$\mathrm{G}=$ Fin $($ wall $)$

Gambar 3. Tipe boundary pada Gambit untuk simulasi numerik, (a) tampak isometri dan (b) tampak bidang $Y Z$

Proses grid independensi diperlukan untuk menentukan struktur grid terbaik dan efisien agar hasil pemodelan mendekati kondisi real. Pada Tabel 2 ditunjukkan meshing benda uji silinder sirkular tanpa fin dengan pemodelan 3D. Setelah dilakukan validasi dengan penelitian yang telah dilakukan oleh Ladjedel, dkk (2011) tentang aliran yang melintasi silinder sirkular, maka 


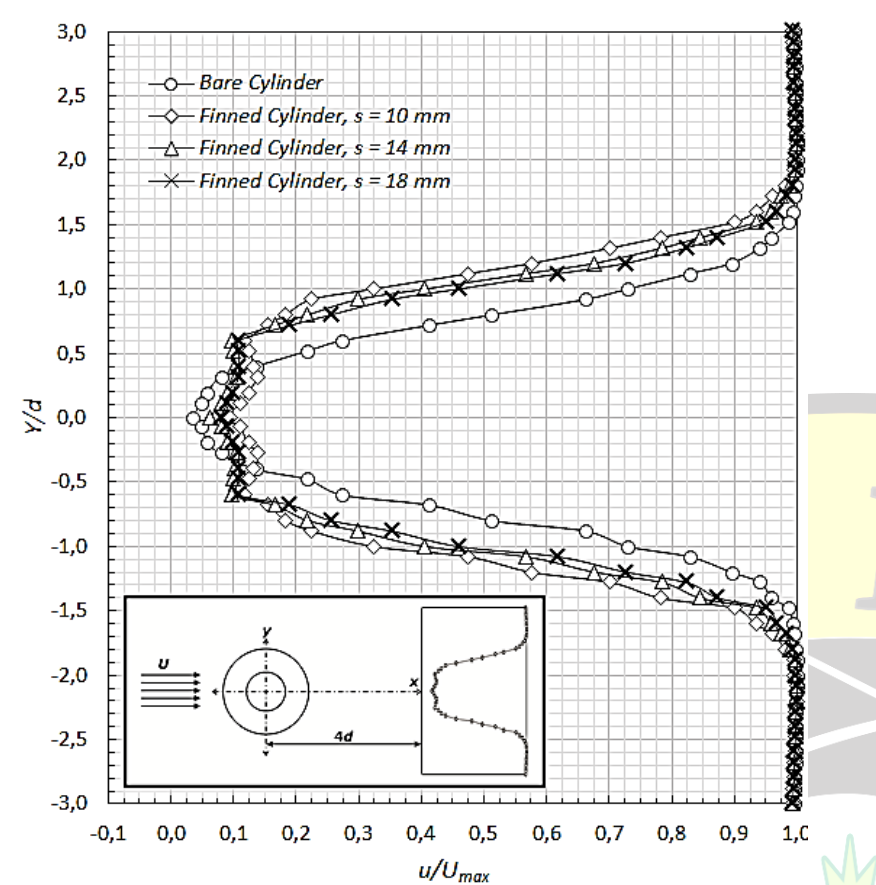

Gambar 4. Profil kecepatan pada daerah wake (jarak $x=4 d$ dari centerline silinder)

Hal yang berbeda terjadi pada profil kecepatan di belakang silinder bersirip, penurunan kecepatan mulai terjadi antara $y / d=1.7$ sampai $y / d=1.8$. Pada silinder bersirip dengan $s=10 \mathrm{~mm}$ kecepatan turun signifikan pada $y / d=0.9$ hingga $y / d=0.6$, kemudian kembali meningkat hingga titik $y / d=0.3$, selanjutnya kembali turun hingga titik simetris. Trend grafik kecepatan seperti ini terjadi karena celah antar fin menjadikan kecepatan aliran udara sedikit meningkat yang dapat diamati pada $x / d=4$ saat $y / d=0.6$ sampai $y / d=0.3$. Visualisasi data ini serta distribusi tekanan di permukaan silinder dan fin yang akan diuraikan pada pembahasan selanjutnya dapat menjadi gambaran awal separasi aliran di permukaan silinder.

Grafik distribusi koefisien tekanan memberikan informasi tentang evolusi aliran yang melintasi kontur permukaan lengkung silinder serta daerah base pressure (daerah bertekanan konstan atau telah terjadi separasi masif). Permukaan yang melengkung menyebabkan kecepatan fluida freestream dan kecepatan fluida pada tepi boundary layer bervariasi. Kecepatan maksimum diperoleh ketika fluida mencapai puncak lengkungan silinder, namun karena adanya efek viskositas, fluida yang mengalir kehilangan energi. Hal ini menjadi sebab fluida tidak mengalir hingga mencapai titik di belakang silinder sebagaimana aliran inviscid.

Pada gambar 5 ditampilkan perbandingan distribusi koefisisen tekanan pada permukaan silinder sirkular dan silinder bersirip pada $\operatorname{Re} 2,5 \times 10^{4}$ di daerah midspan. Kecepatan fluida maksimum pada permukaan silinder sirkular terletak pada titik $75^{\circ}$ yang ditandai dengan koefisien tekanan terendah yaitu -1,245 sedangkan pada silinder bersirip dengan jarak antar fin $10 \mathrm{~mm}, 14 \mathrm{~mm}$, dan $18 \mathrm{~mm}$ kecepatan maksimum masing-masing terletak pada titik $70^{\circ}, 72^{\circ}$, dan $72^{\circ}$, sebagaimana ditampilkan pada gambar 5, pembesaran (1) dengan marker berwarna gelap. Letak titik separasi di permukaan silinder sirkular terjadi pada titik $119^{\circ}$ dan pada permukaan silinder bersirip dengan jarak antar fin $10 \mathrm{~mm}, 14 \mathrm{~mm}$, dan $18 \mathrm{~mm}$ masing-masing pada titik $112^{\circ}, 113^{\circ}$, dan $115^{\circ}$. Hal ini sebagaimana ditampilkan pada pembesaran (2) gambar 5, marker berwarna gelap.

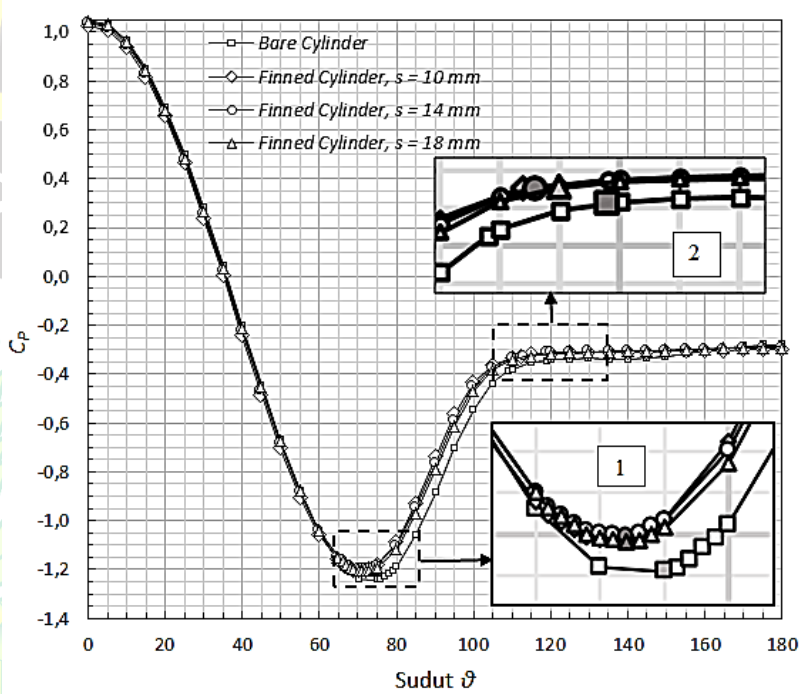

Gambar 5. Distribusi koefisien tekanan di permukaan silinder sirkular dan silinder bersirip simulasi numerik pada $\operatorname{Re} 2,5 \times 10^{4}$ di daerah midspan

Secara visual dapat diamati dari hasil pembesaran grafik pada gambar 5 bahwa pada ruang antar fin, silinder dengan fin pitch $18 \mathrm{~mm}$ menghasilkan grafik $C_{P}$ berada di atas silinder sirkular diikuti silinder dengan fin pitch 14 $\mathrm{mm}$ dan $10 \mathrm{~mm}$, namun perbedaan yang terjadi tidak signifikan. Hal ini menggambarkan pada $\operatorname{Re}=2,5 \times 10^{4}$, semakin rapat jarak antar fin, maka separasi aliran yang terjadi pada ruang antar fin akan terjadi lebih awal. Jarak antar fin menjadi celah yang menyebabkan udara mengalir kurang baik.

Pada gambar 6 ditampilkan profil kecepatan di atas permukaan silinder sirkular dan silinder bersirip pada sudut $90^{\circ}$. Aliran dalam boundary layer di atas silinder sirkular memiliki energi kinetik dan momentum yang lebih besar, hal tersebut ditandai dengan kecepatan maksimum yang dihasilkan lebih besar dibandingkan kecepatan maksimum di atas silinder bersirip lainnya. Kecepatan maksimum yang lebih besar menjadikan profil kecepatan yang terbentuk lebih penuh dibandingkan profil kecepatan di atas silinder bersirip. Sehingga, profil aliran di atas silinder sirkular dapat mengalir lebih jauh di sekeliling silinder sebelum terjadi separasi. 


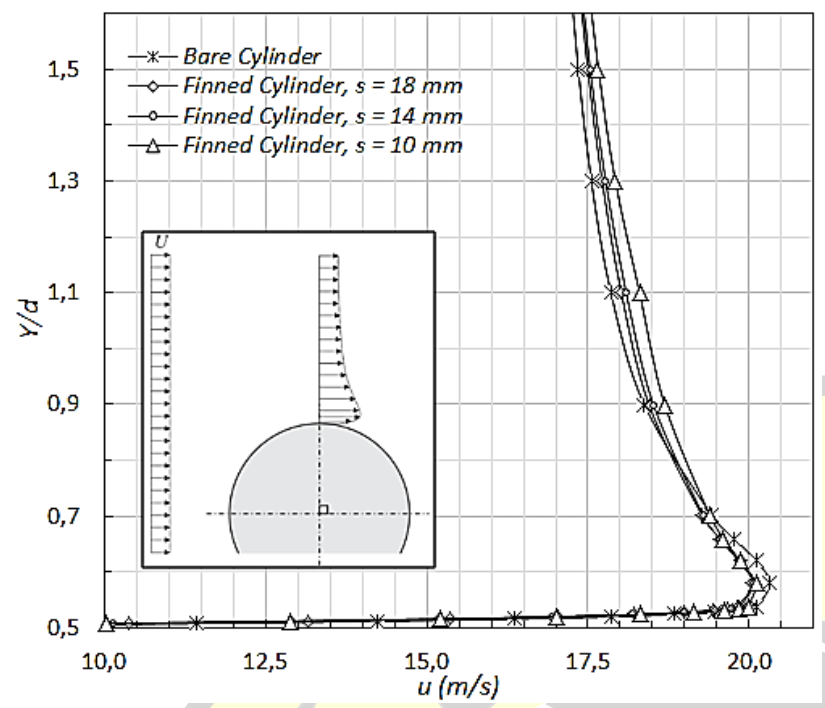

Gambar 6. Perbandingan profil kecepatan hasil simulasi numerik pada posisi $90^{\circ}$ untuk silinder sirkular dan silinder bersirip

\section{Distribusi Koefisien Tekanan $\left(C_{P}\right)$ di Permukaan Fin}

Pola aliran di permukaan fin pada penelitian ini diamati dengan menampilkan distribusi koefisien tekanan di permukaan fin. Pada gambar 7 ditampilkan titik pengambilan data numerik distribusi koefisien tekanan di permukaan fin di dekat daerah midspan. Jarak antar dua titik koordinat radial yang berdekatan di permukaan fin diatur sejauh $30^{\circ}$ dengan titik referensi adalah titik pusat silinder. Sedangkan jarak antar titik dalam satu garis sudut dibedakan dengan koordinat radial nondimensional $(\mathrm{Pr})$ yang didefinisikan sebagai berikut:

$$
\operatorname{Pr}=\frac{r-r_{0}}{R-r_{0}}
$$

Jari-jari silinder yang merupakan titik pangkal fin (fin base) disimbolkan dengan $r_{0}$, sedangkan $R$ adalah jari-jari fin, dan $r$ notasi untuk titik koordinat radial pengambilan data $C_{P}$. Sehingga $P r=0,10$ adalah titik terdekat dengan fin base sedangkan $\operatorname{Pr}=0,90$ merupakan titik terluar pengambilan data $C_{P}$ di permukaan fin.

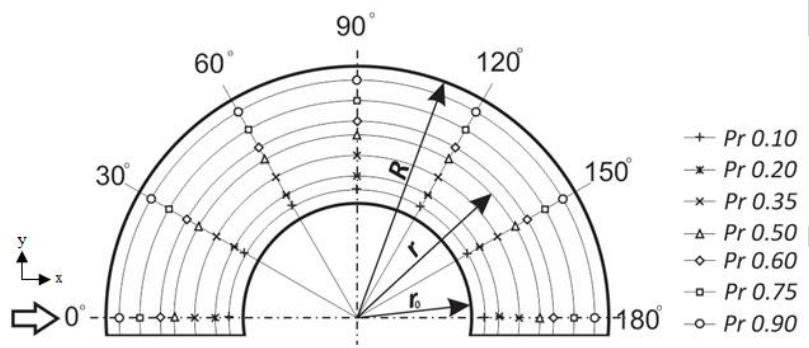

Gambar 7. Posisi pengambilan data koefisien tekanan di permukaan fin

Hasil data numerik distribusi $C_{P}$ di permukaan fin sebagai fungsi koordinat radial nondimensional ditampilkan pada gambar 8 . Sepanjang garis $0^{\circ}$ baik fin pitch $10 \mathrm{~mm}$ dan 18 mm terjadi perbedaan kecepatan di dekat permukaan fin yang disebabkan oleh perkembangan boundary layer. Kecepatan maksimun terjadi pada $P_{r}=0,9$ atau pada daerah terluar fin, selanjutnya kecepatan terus mengalami penurunan hingga $P_{r}=0,1$ yang ditandai dengan peningkatan koefisien tekanan ke arah fin base pada gambar 8. Selain pengaruh perkembangan boundary layer, variasi kecepatan di permukaan fin sepanjang garis $0^{\circ}$ disebabkan juga oleh penurunan tekanan sepanjang dinding vertikal silinder bersirip.

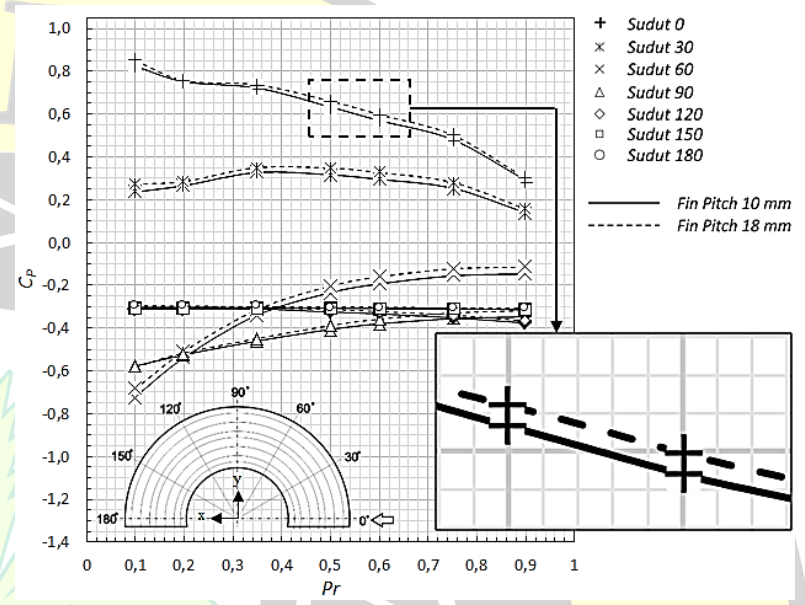

Gambar 8. Perbandingan distribusi koefisien tekanan simulasi numerik di permukaan fin pada fin pitch $10 \mathrm{~mm}$ dan $18 \mathrm{~mm}$ yang berdekatan dengan midspan sebagai fungsi koordinat radial nondimensional.

Pada fin pitch $10 \mathrm{~mm}$, penurunan tekanan yang cukup signifikan terjadi di permukaan silinder sepanjang garis sudut $60^{\circ}$ hingga mencapai koefisien tekanan terendah -0,72 saat $P_{r}=0,1$ sebagaimana ditunjukkan pada gambar 8 . Hal ini terjadi karena aliran fluida memasuki daerah lengkungan silinder dengan kecepatan maksimum. Posisi pada sudut $150^{\circ}$ dan $180^{\circ}$ adalah daerah wake atau daerah separasi masif sehingga distribusi koefisien tekanan relatif konstan di permukaan fin.

Karakteristik aliran pada daerah antar fin dipengaruhi oleh panjang relatif fin terhadap diameter silinder sirkular dan jarak antar fin.

Pada gambar 8 ditampilkan pula perbandingan distribusi koefisien tekanan di permukaan fin pada jarak antar fin 10 $\mathrm{mm}$ dan $18 \mathrm{~mm}$. Data ditampilkan sebagai fungsi koordinat radial nondimensional, diambil dari permukaan fin yang berdekatan dengan midspan. Tren grafik distribusi koefisien tekanan di permukaan fin pada silinder bersirip dengan jarak antar fin $10 \mathrm{~mm}$ dan $18 \mathrm{~mm}$ menunjukkan hasil yang identik. Namun pada permukaan fin dengan fin pitch $18 \mathrm{~mm}$, grafik distribusi $C_{P}$ yang dihasilkan memiliki nilai sedikit lebih besar dibandingkan dengan nilai distribusi $C_{P}$ pada permukaan fin dengan fin pitch $10 \mathrm{~mm}$. Hal ini disebabkan jarak antar fin $10 \mathrm{~mm}$ yang lebih sempit menjadikan kecepatan aliran sedikit 
lebih besar saat memasuki celah antar fin, dan ditunjukkan dengan nilai $C_{P}$ yang lebih kecil dibandingkan silinder bersirip dengan fin pitch $18 \mathrm{~mm}$.

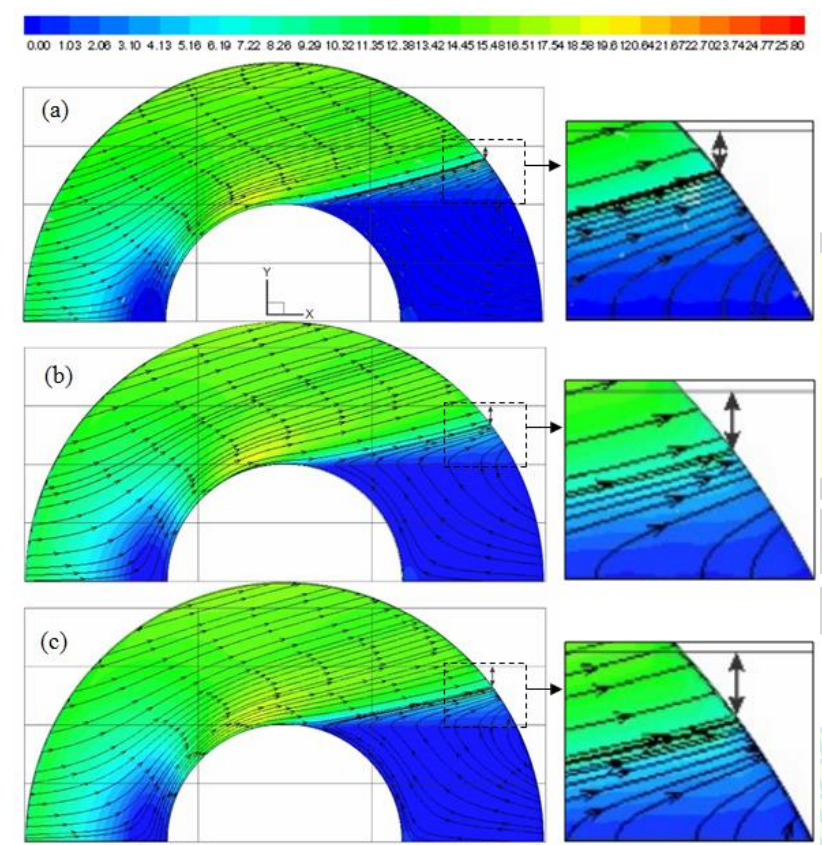

Gambar 9. Pathline dan kontur kecepatan $(\mathrm{m} / \mathrm{s})$ di permukaan fin untuk masing-masing variasi jarak antar fin; (a) pitch $10 \mathrm{~mm}$, (b) pitch $14 \mathrm{~mm}$, (c) pitch $18 \mathrm{~mm}$

Pola aliran di permukaan fin ditampilkan pada gambar 9. Ketika jarak antar fin meningkat, posisi separasi aliran dan vorteks bergerak mendekat ke daerah di belakang silinder, sebagaimana ditunjukkan dengan garis-garis dua anak panah pada pembesaran gambar 9. Garis panah terpanjang terhadap garis bantu vertikal adalah garis panah permukaan dengan fin pitch $18 \mathrm{~mm}$, kemudian 14 $\mathrm{mm}$, dan $10 \mathrm{~mm}$. Hasil ini menunjukkan bahwa udara tidak mengalir dengan baik pada daerah tersebut untuk fin pitch yang sempit. Kecendrungan ini identik dengan pola aliran di permukaan fin yang dilakukan oleh Yoshida dkk (2006) sebagaimana ditampilkan pada gambar 10.

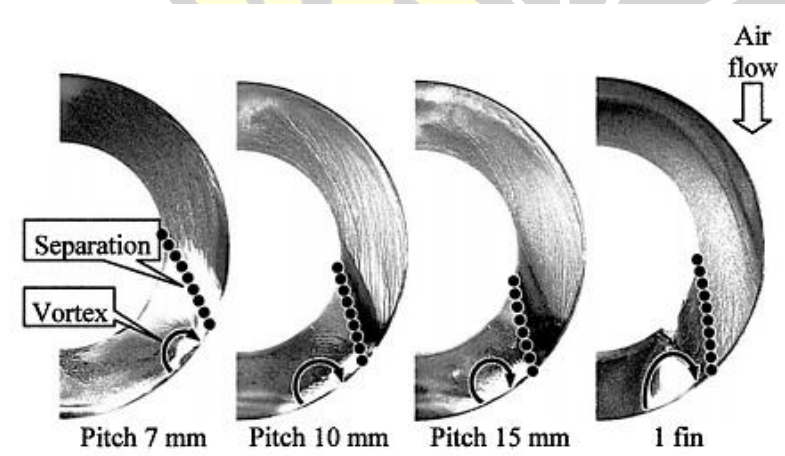

Gambar 10. Pengamatan pola aliran pada permukaan fin dengan eksperimen (Yoshida dkk, 2006)

\section{PENUTUP}

\section{Simpulan}

1. Letak titik separasi di permukaan silinder sirkular terjadi pada titik $119^{\circ}$ dan pada permukaan silinder bersirip dengan jarak antar fin $10 \mathrm{~mm}, 14 \mathrm{~mm}$, dan 18 mm masing-masing pada titik $112^{\circ}, 113^{\circ}$, dan $115^{\circ}$. Oleh karena itu, dapat disimpulkan bahwa semakin rapat jarak antar fin, maka separasi aliran yang terjadi pada ruang antar fin akan terjadi lebih awal.

2. Ketika jarak antar fin semakin rapat, posisi separasi aliran dan vorteks di permukaan fin semakin lebar. Hal ini menunjukkan bahwa udara tidak mengalir dengan baik pada daerah tersebut untuk fin pitch yang sempit.

3. Simulasi numerik dengan pendekatan 3D-steady flow Reynolds Averaged-Navier Stokes (RANS) dan RNG $k$ - $\varepsilon$ cukup baik untuk mengamati karakteristik aliran di sekitar silinder bersirip.

\section{Saran}

Beberapa saran dapat diberikan dari hasil pengamatan yang telah dilakukan pada penelitian dengan menggunakan metode eksperimen dan simulasi numerik ini. Saran-saran berikut diharapkan mejadi acuan untuk penelitian-penelitian selanjutnya terutama yang berkaitan dengan penelitian aliran melalui silinder bersirip:

1. Pengambilan data eksperimen sebaiknya pada kondisi temperatur dan tekanan lingkungan yang sama untuk berbagai variasi penelitian. Hal ini dimaksudkan agar data yang diperoleh dari variasi tersebut tidak terpengaruh dengan kondisi lingkungan yang ada.

2. Simulasi numerik dapat dilakukan dengan membandingkan beberapa model turbulen untuk mendapatkan model yang mendekati hasil uji eksperimen.

\section{DAFTAR PUSTAKA}

Khashehchi, K., Abdi, I. A., Hooman, K., Roesgen, T. (2014), "A Comparison between The Wake behind Finned and Foamed Circular Cylinders in CrossFlow", Experimental Thermal and Fluid Science, Vol. 52, hal. 328-338.

Pis'mennyi, E.N., Terekh, A.M., Polupan, G.P., Mariscal, I. C., Sanchez, S. F. (2014), "Universal Relations for Calculation of The Drag of Transversely Finned Tube Bundles", International Journal of Heat and Mass Transfer, Vol. 73, hal. 293-302.

Pis'mennyi, E.N. (2012), "Regularities of Flow and Heat Transfer at The Surface of Transversely Finned 
Tubes", International Journal of Heat and Mass Transfer, Vol. 55, hal. 5016-5031.

Triyogi, Y., Suprayogi, D., Spirda, E. (2009), "Reducing The Drag on a Circular Cylinder by Upstream Installation of an I-Type Bluff Body as Passive Control" Journal Mechanical Engineering Science, Vol. 223, hal. 2291-2296.

Widodo, Wawan A., Triyogi, Y., Indiyono, P., Aryawan, Wasis D. (2009), "Pengendalian Aliran Pasif pada Silinder Sirkular Disturbance Body Berbentuk Silinder Elip (AR 1/4)" Jurnal Teknik Mesin, Vol. 11, No. 1, hal $1-11$.

Yoshida, M., Ishihara, S., Murakami, Y., Nakashima, K., Yamamoto, M. (2006), "Air-Cooling Effects on a Motorcycle Engine", JSME International Journal, Vol. 49, No.3, hal. 869-875.
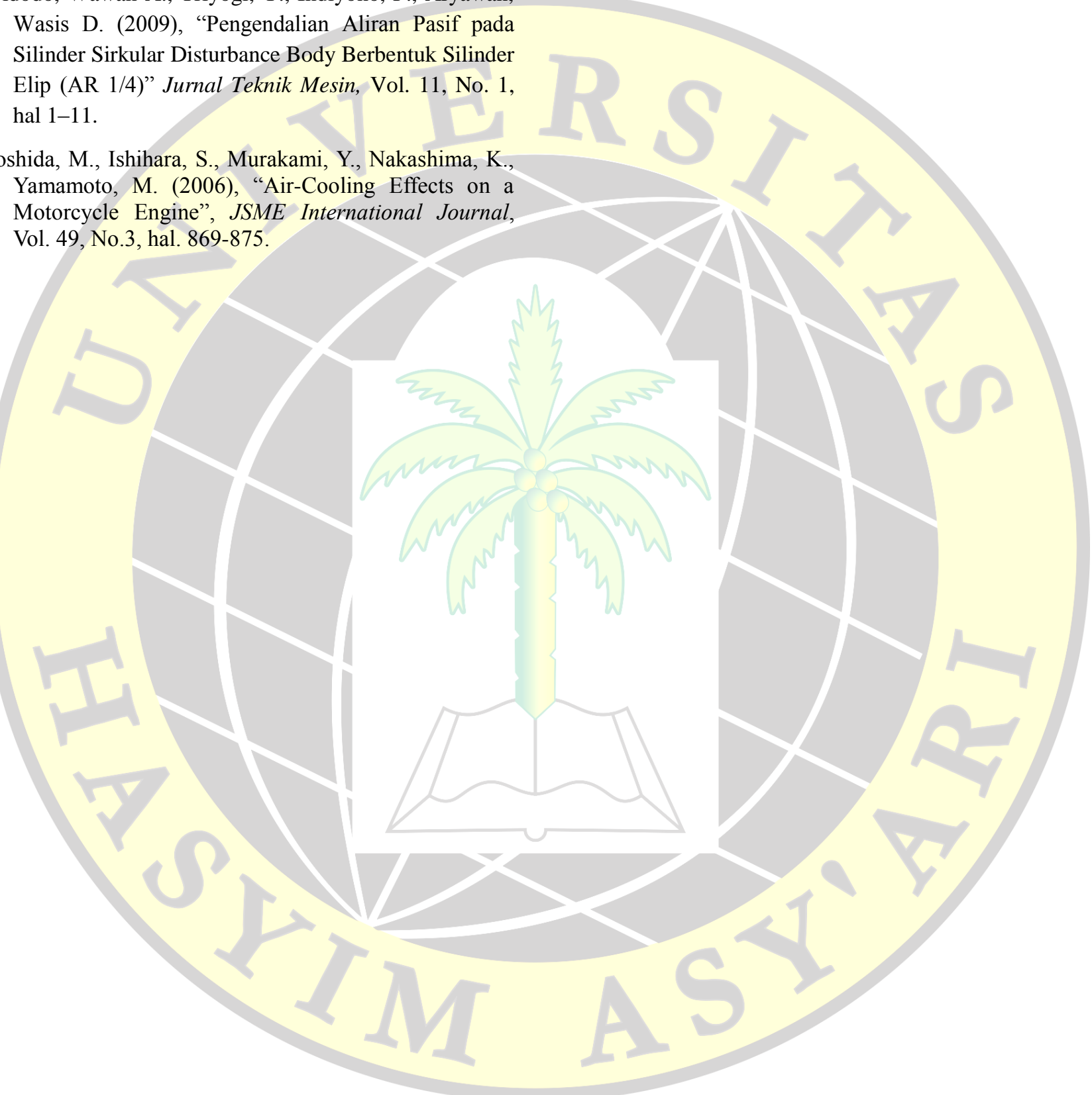